\title{
Icing Sugar Spleen/Perisplenitis Cartilaginea: A Case Report
}

Sunil Y Swami*, Apurva A Bhure, Sandhya B Narwade and Arvind G Valand

Department of Pathology, Swami Ramanand Teerth Rural Medical College, Ambajogai, Beed, Maharashtra 431517, India

\begin{abstract}
Spleen, being the largest organ of the mononuclear phagocytic system is involved in many systemic inflammations, generalized haematopoietic disorders as well as metabolic disorders. Perisplinitis, also known colloquially as "icing sugar spleen", is a common autopsy finding. The capsule of the spleen becomes nodular, thickened and fibrotic and it appears as though the spleen has been dipped in white icing. Perisplenitis is seen as creamy yellow to white exudates or firm glistening "icing-like" plaques on the capsular surface, indicating active acute or regressed infection, respectively. It is usually secondary to generalised peritonitis or extension from local infection. It has been reported as part of Curtis-Fitz-Hugh syndrome or a common accompaniment to cirrhosis of the liver. Massive splenomegaly with sugar icing spleen is also seen in chronic myeloid leukemia and may be seen in sickle cell anaemia. Here we present a case of perisplinitis in a 65 years old male patient as an incidental autopsy finding.
\end{abstract}

Keywords: Perisplenitis cartilaginea; Icing sugar; Fibrous perisplinitis; Hyaline perisplinitis

\section{Introduction}

Spleen is the largest organ of the mononuclear phagocytic system and is involved in all systemic inflammations, generalized haematopoietic disorders as well as metabolic disturbances [1,2].

Perisplinitis, also known colloquially as "icing sugar spleen", is a common autopsy finding. The capsule of the spleen becomes nodular, thickened and fibrotic, and it appears as though the spleen has been dipped in white icing. Over time, calcification may supervene. Perisplinitis can complicate any inflammatory process in the abdomen or pelvis and splenic sepsis, and it is also seen in patients with chronic obstructive pulmonary disease. It has been reported as part of CurtisFitz-Hugh Syndrome [3].

Perisplenitis is seen as creamy yellow to white exudates or firm glistening "icing-like" plaques on the capsular surface, indicating active acute or regressed infection, respectively. It is usually secondary to generalised peritonitis or extension from local infection [4].

Irregular pale tan plaques of collagen over the purple capsule known as "sugar icing" or "hyaline perisplenitis" which follows the splenomegaly and/or multiple episodes of peritonitis that are a common accompaniment to cirrhosis of the liver [5]. Splenic infarcts and perisplenitis may give rise to left hypochondriac pain [6].

\section{Case Report}

During an autopsy on a 65 years old male patient, incidentally we came across a mildly enlarged spleen of size $10 \times 7.5 \times 5 \mathrm{~cm}$. External surface showed multiple, variable sized, whitish nodules and plaques ranging from $2 \mathrm{~mm}$ to $1 \mathrm{~cm}$ over the convex surface of the splenic capsule and without involvement of splenic parenchyma as seen on cut surface (Figure 1).

On microscopy, these nodules and plaques were composed of closely packed hyalinised collagen fibres over the capsule without involvement of splenic parenchyma (Figure 2).

\section{Discussion}

Many surgical pathologists approach the spleen with trepidation, thus indirectly reinforcing the old axiom that the spleen is an organ of mystery. The reason may be related to the fact that many pathologists initially learn splenic pathology at post-mortem examination; at autopsy, spleen frequently is autolysed, and the normal histologic landmarks are obscured [7]. Perisplenitis is very common incidental observation at post-mortem examination, remain unexplained in pathogenetic terms. It takes the form of pearly white thickening of splenic capsule to form irregular plaques or occasionally, a dense rind on the surface of the organ. The convex surface usually more severely affected than the concave, medial aspect of the spleen [8]. Perisplenitis is an active or regressed phase. When active, part or the entire capsule

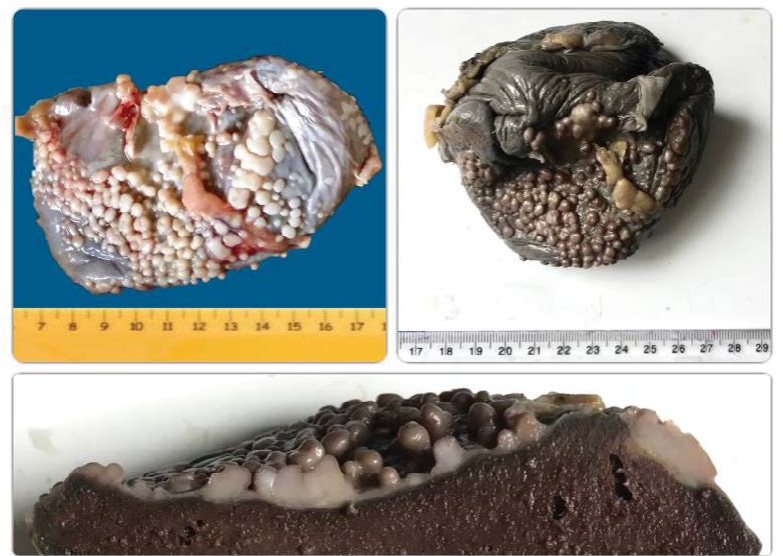

Figure 1: Hyaline perisplinitis (Gross and Cut surface): Multiple grayish white nodules and plaques on the surface of the splenic capsule.

*Corresponding author: Swami SY, Department of Pathology, Swami Ramanand Teerth Rural Medical College, Ambajogai, Beed, Maharashtra 431517, India, Tel: +91-9860006075; E-mail: drsys02@gmail.com

Received December 20, 2017; Accepted January 12, 2018; Published January 23, 2018

Citation: Swami SY, Bhure AA, Narwade SB, Valand AG (2018) Icing Sugar Spleen/Perisplenitis Cartilaginea: A Case Report. J Cytol Histol 9: 497. doi: 10.4172/2157-7099.1000497

Copyright: (c) 2018 Swami SY, et al. This is an open-access article distributed under the terms of the Creative Commons Attribution License, which permits unrestricted use, distribution, and reproduction in any medium, provided the original author and source are credited. 
Citation: Swami SY, Bhure AA, Narwade SB, Valand AG (2018) Icing Sugar Spleen/Perisplenitis Cartilaginea: A Case Report. J Cytol Histol 9: 497. doi: $10.4172 / 2157-7099.1000497$

Page 2 of 2

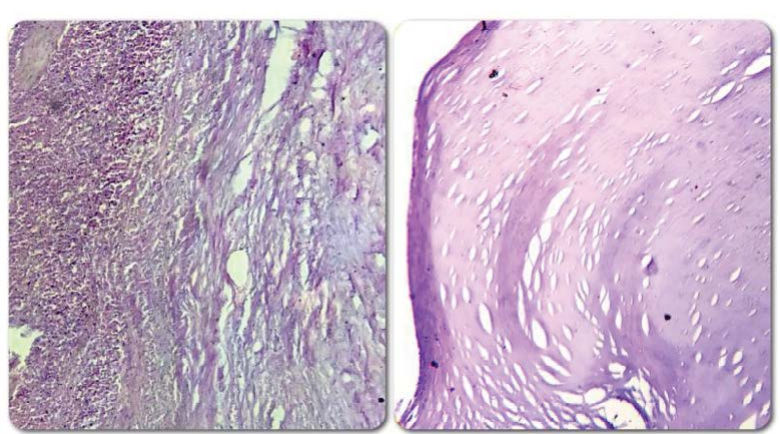

Figure 2: Hyaline perisplinitis: Photomicrograph shows nodule composed of compactly arranged hyalinized collagenous tissue with thickened splenic capsule (H\&E: 10X and 40X).

is covered with fibrin which hides the surface sheen and roughens the capsule. The cause is generalised peritonitis or local inflammation spreading from neighbouring organs. Alternatively, it may come from within the spleen. Splenitis, in the sense of infection, is uncommon. Perisplenitis is more likely to be a reaction to thrombosis or infarction. The final stage of perisplenitis is when exudate has long ago been organised, leaving a pure white smooth or wrinkled thickening generally local and often multiple (hyaline perisplenitis). The plaques are several millimetres thick and often have calcium deposits which cannot be cut through. Even greater and quite diffuse thickening is caused by polyserositis; the capsule displays the sugar icing effect seen also around the liver and in the pericardium [9]. Massive splenomegaly with sugar icing spleen is also seen in chronic myeloid leukemia [7]. In the sickle cell anaemia, focal accentuation of capsular fibrosis leads to a "sugar-coated" appearance in the spleen [10]. Perisplenitis cartilaginea is the name derived from hyaline transformation of connective tissue where there is loss of fibrous appearance due to high degree packing of collagen fibers and accumulation of nonfibrillar components (giant proteoglycans e.g. seen in cartilaginous tissue) there by having homogenous translucent character. Capsular fibrosis of the spleen is typically asymptomatic and of little clinical significance. Its importance is in recognizing that it is a benign indolent process and in not confusing it with primary or metastatic malignant disease [11].

\section{Conclusion}

It has been reported as part of Curtis-Fitz-Hugh syndrome or a common accompaniment to cirrhosis of the liver. Massive splenomegaly with sugar icing spleen is also seen in chronic myeloid leukemia and may be seen in sickle cell anaemia. Here we present a case of perisplinitis in a 65 years old male patient as an incidental autopsy finding. No MRI was done prior to autopsy. Perisplenitis was an incidental finding during autopsy.

\section{References}

1. Kumar V, Abbas AK, Fausto M (2014) Robbins and Cotran pathologic basis of disease. Elsevier Saunders, Philadelphia (7thedn), pp: 702-705.

2. Babina S, Gayatri DP, Sharmila L, Barindra SA Kaushik D (2014) Histomorphological pattern of splenectomy specimens: A five-year study in a tertiary teaching hospital. IOSR-JDMS 13: 40-43.

3. Gatt D, Jantet G (1987) Perisplinitis and perinephritis in the Curtis-Fitz-Hugh syndrome. British J Surg 74: 110-112.

4. Daksha P, Subhash $Y(2017)$ Examination of the hemolymphatic system. In Dhaneshwar L, Pradeep V (eds.) Autopsy Practices (1stedn), Jaypee, New Delhi, pp: 90-97.

5. Sarin SK, Khanna R (2014) Non-cirrhotic portal hypertension. Clin Liver Dis 18: $451-476$.

6. Jerome SB (2004) The spleen. In: Sternberg's diagnostic surgical pathology. Jaypee Publications. Wolters Kluwer/Lippincott Williams and Wilkins. Philadelphia (4thedn), pp: 849-878.

7. Willkins BS, Wright DH (2009) Metastasis and miscellaneous conditions. In Illustrated pathology of the spleen. Cambridge university press. New York 151162.

8. Rezek PR, Millard M (1963) Pancreas and spleen. In: Autopsy pathology. Chares C Thomas. 544-576.

9. Kuntz E, Kuntz HD (2008) Systemic diseases and liver. In: Hepatology text book and atlas. Springer Medizin Verlag Heidelberg, Germany (3rdedn), pp: 838-851.

10. Riccardo V, Mary Z, Alina DF, Raphael R (2012) Hematopathology. In: Rubin R, Strayer DS (eds.) Rubin's pathology: Clinicopathological foundation of medicine (6thedn), Wolters Kluwer/Lippincott Williams and Wilkins. Philadelphia, pp: 947-1036.

11. Janaki M, Hayath MS, Rao GM, Chennappa $Y$ (1998) Marked perisplenitis in gastric carcinoma. Indian J Gastroenterology 17: 66-67. 